|| ISSN(online): 2589-8698 || ISSN(print): 2589-868X |

International Journal of Medical and Biomedical Studies

Available Online at www.ijmbs.info

NLM (National Library of Medicine ID: 101738825)

Index Copernicus Value 2019: 79.34

Original Research Article

Volume 5, Issue 10; October: 2021; Page No. 100-103

\title{
SONOGRAPHIC IMAGING OF ACUTE SCROTAL PAIN
}

\author{
Dr. Naman Saxena ${ }^{1}$ (PG Resident $2^{\text {nd }}$ Year), Dr. Amlendu Nagar ${ }^{2}$ (Professor), Dr. Sheetal Singh ${ }^{3}$ (Professor) \& \\ Dr. Pradeep Ahirwar ${ }^{4}$ (PG Resident $2^{\text {nd }}$ Year)
}

Dept. of Radio diagnosis, Index Medical College Hospital \& Research Centre, Indore 1,2,3\&4 $^{2}$

Article Info: Received 20 July 2021; Accepted 21 September 2021

DOI: https://doi.org/10.32553/ijmbs.v5i10.2257

Corresponding author: Dr. Pradeep Ahirwar

Conflict of interest: No conflict of interest.

\begin{abstract}
Background: An acute scrotum is defined as acute pain with or without scrotal swelling, may be accompanied by local signs or general symptoms. Acute scrotal pain is a medical emergency. Depending on cause, the management is entirely different. Torsion of testis and strangulated hernia are surgical emergency; whereas, epididymo-orchitis is treated by medicines. Testicular trauma and obstructed hernia can be differentiated by taking history from patient. Clinical /Physical examination adds only a little information. Color Doppler ultrasound is the modality of choice to differentiate testicular torsion from inflammatory conditions.

Aim of Study: The aim of this study is to observe the epidemiology of acute scrotum and their presentation, there by facilitating a systematic approach in identifying those patients who need early intervention to decrease associated morbidity and mortality. Conclusion: Acute scrotum is a common case seen in the today's scenario with considerable mortality and morbidity. In our study acute epididymo-orchitis was the commonest cause followed by torsion of testis the primary objective of management of acute scrotum is to avoid testicular loss. Acute scrotal swellings are common in younger \& middle age individuals with variable symptoms. These cases need careful examination, proper evaluation and prompt treatment. The likelihood of testicular salvage in torsion depends on the interval between onset of pain and surgical intervention. Routine clinical examination gives only a little information. Doppler ultrasound assessment of patients at intermediate clinical risk of testicular torsion significantly reduced the frequency of negative surgical explorations without increased rate of missed testicular torsions.(1) In the imaging algorithm for testicular torsion in childhood, we differentiate between the two main entities, the peri- and neonatal torsion and torsions in children and infants older than 1 month. Imaging should not cause any delay in diagnosis but contribute to increase the specificity of diagnosis of testicular torsion in order to avoid unnecessary surgical explorations. (2)
\end{abstract}

Keywords: Sonographic Imaging in Acute Scrotal Pain.

\section{Introduction}

The ability to confidently establish a surgical versus a nonsurgical diagnosis for acute scrotal pain is important. The benefits of early surgery for testicular salvage in ischemic disease, primarily torsion of the testis, are wellknown; but must be balanced against the costs of operating unnecessarily on a large number of patients with nonsurgical disease, primarily acute epididymo-orchitis. Acute scrotum is defined as acute pain with or without scrotal swelling, may be accompanied by local signs or general symptoms. The most common differential diagnoses of the acute scrotum include: i) Epididymoorchitis ii) Torsion of testis iii)Torsion of appendix testis iv) Fournier's gangrene v) Hematocele vi) Pyocele vii) Scrotal wall abscess.[3] This appropriate discussion, however, will be limited to patients with acute pain who have no history of trauma and no history of a mass before the onset of pain. There is, however, overlap in the clinical presentation of the different causes of acute scrotal pain. Imaging in clinically equivocal cases may lead to an early diagnosis of testicular torsion, and thus, decrease the number of unnecessary surgeries. There is no definite protocol of acute scrotum screening for the primary care physicians to follow. Early detection of testicular torsion through color Doppler is the only means to reduce the burden of morbidity. The article emphasizes the importance and protocol of screening of patient with acute scrotal pain to create awareness among primary healthcare providers so as to detect testicular torsion at the earliest, so immediate surgery can be performed to salvage the testis as well as to rule out testicular torsion so that unnecessary surgery can be avoided. A study comparing primary scrotal exploration and initial ultrasound (US) examination with exploration for positive US results or a high clinical suspicion of torsion, showed that US obviated the need for exploration in many patients and thus shortened hospital stays [4].

This clinical syndrome most often presents with acute onset of pain and swelling. Acute scotrum can also be caused by either sexually transmitted pathogens ascending from the urethra or non-sexually transmitted uropathogens spreading from the urinary tract $\mathrm{TB}$ can cause focal epididymitis, draining sinus, or classical beading of the vas 
deferens with extensive involvement (5).Intermittent" testicular torsion is a condition in which patient presents with classical history of torsion but clinical examination and USG scrotum are normal (6) Perinatal testicular torsion, defined as torsion occurring in the prenatal period or in the first month after birth, Most are extravaginal, and intravaginal torsion is rare.(7)

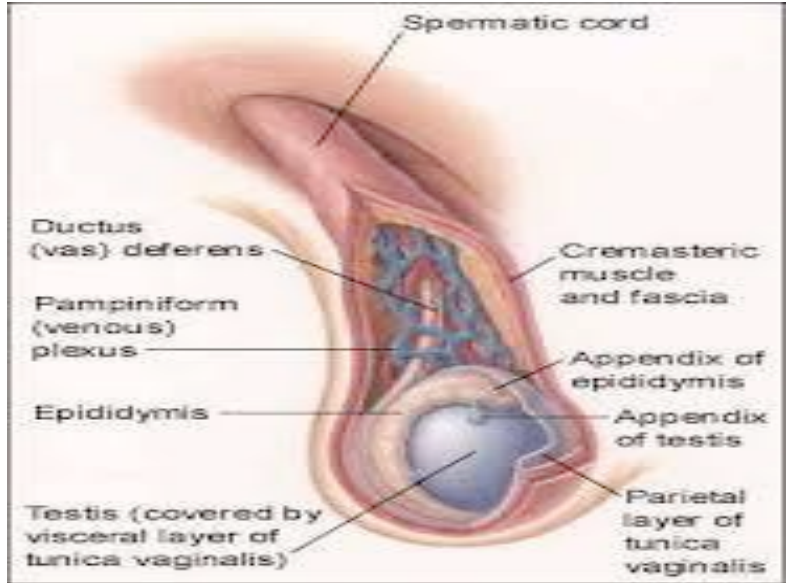

Figure 1: Testis Anatomy

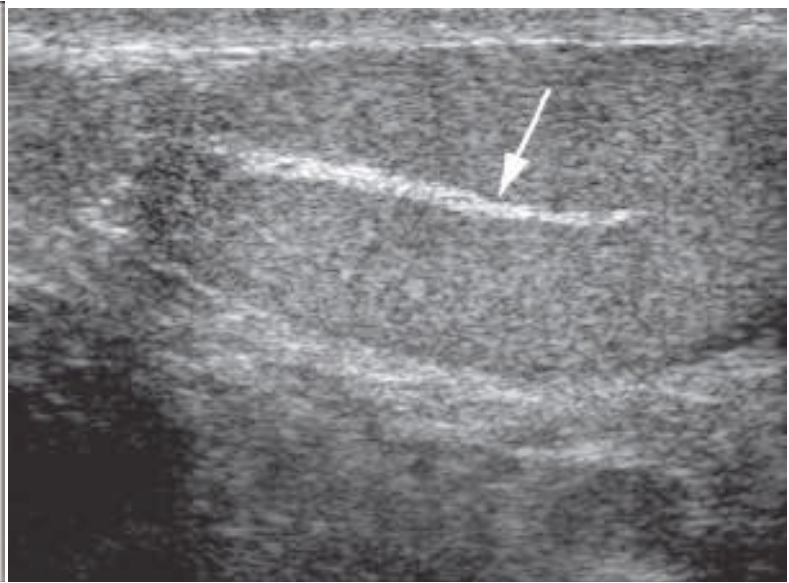

Figure 2: Mediastinum Testis (arrow)

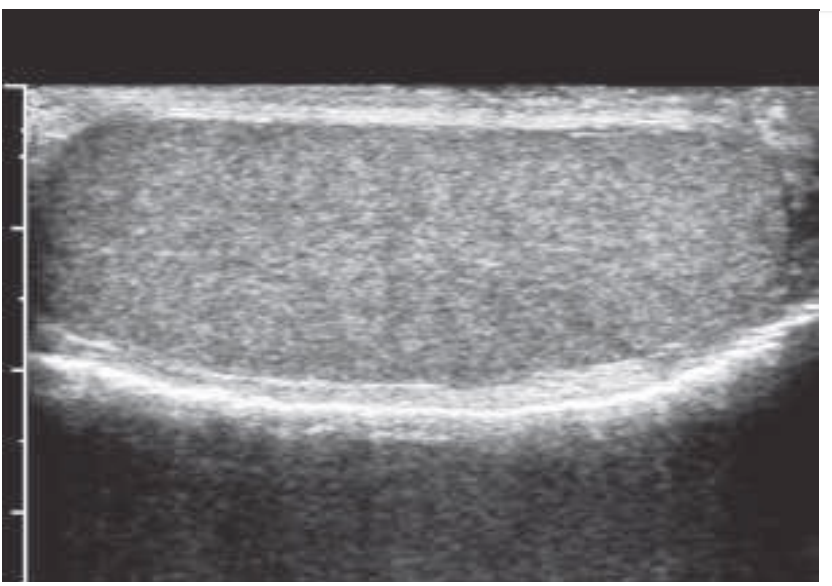

Figure 3: Normal Homogeneous echo texture

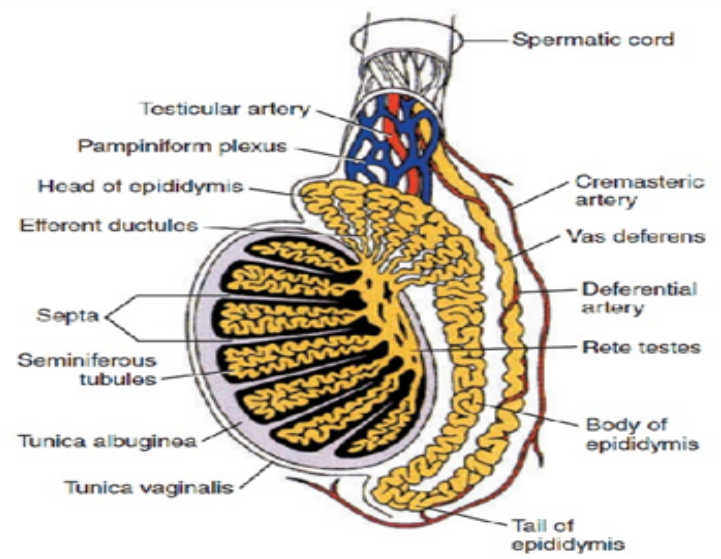

Figure 4: Normal Intrascrotal Anatomy

Figure 1: Normal Anatomyof Testis (5), (10)

\section{Material \& Method}

GE Voluson S8 USG and USG seimen Acuson300USG. A total of 60 patients were taken in our study from february2021-July2021 referred from OPD/ER. The study was conducted by retrospective and observational analysis.

\section{Inclusion Criteria:}

1. All cases of acute scrotum admitted in our medical college

2. Referred from OPD/ER.

\section{Exclusion Criteria:}

1. Patients not willing for getting investigated.

2. Patients presented with chronic scrotal pain

Results: A total of 60 cases were included in the study group.

1. Age Distribution

2. Predisposing Factors.

3. Duration of Symptoms

4. Incidence of various causes of acute scrotum 
Table 1: Age Distribution

\begin{tabular}{|l|l|l|}
\hline Age Distribution & No. of Cases & Percentage \\
\hline$<20$ & 10 & 16.6 \\
\hline $20-40$ & 20 & 33.4 \\
\hline $41-60$ & 20 & 33.4 \\
\hline$>60$ & 10 & 16.6 \\
\hline
\end{tabular}

Max cases reported in age group 20-60 (33.4 per)

Table 2: Predisposing Factors

\begin{tabular}{|l|l|l|}
\hline Factor & No. of Cases & Percentage \\
\hline Trauma & 12 & 20 \\
\hline Urinary Infection & 09 & 15 \\
\hline Similar Episodes In Past & 07 & 11.7 \\
\hline Diabetes Mellitus & 09 & 15 \\
\hline Idiopathic & 23 & 38.3 \\
\hline
\end{tabular}

Max cases are idiopathic (38.3) min are cases have similar past episode (11.7)

Table 3: Duration of Symptoms

\begin{tabular}{|l|l|l|}
\hline Duration & No. Of Cases & Percentage \\
\hline $0-24$ Hrs & 15 & 25 \\
\hline $1-3$ Days & 24 & 40 \\
\hline $4-7$ Days & 13 & 21.7 \\
\hline 7 Days & 8 & 13.3 \\
\hline Total & 60 & 100 \\
\hline
\end{tabular}

Max cases reported in duration of 1-3 days (40per)

Table 4: Incidence of Various Causes Of Acute Scrotum

\begin{tabular}{|l|l|l|}
\hline Diagnosis & No. Of Cases & Percentage \\
\hline Epididymo - Orchitis & 23 & 38.3 \\
\hline Torsion Of Testis & 11 & 18.3 \\
\hline Torsion Of Appendix Of Testis & 04 & 6.7 \\
\hline Fournier's Gangrene & 06 & 10 \\
\hline Hematocele & 03 & 05 \\
\hline Pyocele & 11 & 18.3 \\
\hline Scrotal Wall Abscess & 02 & 3.3 \\
\hline
\end{tabular}

Max. Incidence of Epididmyo-orchitis (38.3 per) and min incidence is scrotal wall abscess (3.3)

\section{Discussion}

Acute scrotal pain is a medical emergency. Depending on cause, the management is entirely different.Torsion of testis is surgical emergency; whereas, epididymo-orchitis is treated by medicines In these situations, USG with color Doppler is valuable in differentiating between medically treatable and surgical emergency of scrotum and avoiding unnecessary disastrous surgical exploration.[8] Now, USG with high frequency transducer in combination with color Doppler has become the imaging modality of choice for evaluation of acute scrotum. Testicular torsion pain is of acute and severe in nature and usually begins to reduce after 6 hours of onset(9)
Result

Acute scrotum is a common case seen in the today's scenario with considerable mortality and morbidity. Acute epididymo-orchitis was the commonest cause followed by torsion of testis.

In our study most common age group involved was 4160yrs followed by 21-40yrs. Acute epididymo-orchitis was the commonest cause for acute scrotum accounting for $33.3 \%$ of total cases, followed by torsion of testis which accounted for $21.7 \%$, fournier's gangrene $(13.3 \%$ ), pyocele $(13.3 \%)$, hematocele $(10 \%)$, torsion of appendix of testis (5\%), scrotal wall abscess (3.4\%). Majority of the patients presented with complaints for about 1-3 days. Pain in the 
scrotum was the commonest presenting symptom followed by swelling of scrotum.

\section{References}

1. Doppler ultrasound improves diagnostic accuracy for testicular torsionKarl Teurneau-Hermansson, Igor Zindovicb,Jon Jakobssona,Anders Navntoft,Ann NozohorEkmark.Martin Salöc

2. Riccabona $\mathrm{M}$, Darge $\mathrm{K}$, Lobo $\mathrm{ML}$, et al. ESPR Uroradiology Taskforce--imaging recommendations in paediatricuroradiology, part VIII: retrograde urethrography, imaging disorder of sexual development and imaging childhood testicular torsion. PediatrRadiol 2015; 45:2023-8.

3. Remer EM, Casalino DD, Arellano RS, Bishoff JT, Coursey CA, Dighe M, et al. ACR Appropriateness Criteria ${ }^{\circledR}$ acute onset of scrotal pain-without trauma, without antecedent mass. Ultrasound Q. 2012; 28:4751.

4. Lam WW, Yap TL, Jacobsen AS, Teo HJ. Colour Doppler ultrasonography replacing surgical exploration for acute scrotum: Myth or reality? Pediatr Radiol. 2005; 35:597-600.

5. Watkin, N.A., Reiger, N.A., and Moisey, C.U. (1996) Is the conservative managementof the acute scrotum justified on clinical grounds? Br. J. Urol. 78,623-627.

6. Singh Inderbir.Urogenital System. In: Singh I, editor. Human Embryology.5th edition. New Delhi: Macmillan India Limited; 1991.p.305-309

7. Sanguesa Nebot C, Llorens Salvador R, Pico Aliaga S, GarcesInigo E. Perinatal testicular torsion: ultrasound assessment and differential diagnosis. Radiologia 2017;59:391-400.

8. J. Ben Chaim, I. Leibovitch, J. Ramon, D. Winberg and B. Goldwasser, "Etiology of Acute Scrotum at Surgical Ex- ploration in Children, Adolescents and Adults," European Urology, Vol. 21, No. 1, 1992, pp. $45-47$

9. Sparks JP (1971) Torsion of the testis. Ann R CollSurgEngl 49: 77-91.

10. Diagnostic ultrasound 5 edition Carol .M Rumack, Deborah Levine. 